\title{
Bridges to biotechnology and
}

\section{bioentrepreneurship: improving diversity in the biotechnology sector}

\author{
A summer pipeline program provides under-represented students from around the United States with exposure \\ and first-hand training to advance their careers in the biotechnology industry.
}

iotechnology — a rich sector of products, intellectual property and $\mathrm{R} \& \mathrm{D}$ services - is a cornerstone to serving the world's health-related needs for all demographics; but in the United States, the industry's workforce does not reflect the demographics it serves, to the detriment of both the field and the US population. African Americans and other historically underserved and marginalized populations are particularly under-represented in the industry. To ameliorate these disparities, we created a five-week summer pipeline program, "Bridges to Biotechnology \& Bioentrepreneurship" (B2BB), hosted at Morehouse School of Medicine (MSM), a historically Black college. This first-of-its-kind online program provides under-represented students from around the United States with exposure and first-hand training to advance their careers in the biotechnology industry and/or start their own bioventures. Unlike in any other program, students experience first-hand both the science and business aspects of biotechnology, including defining a product's value proposition, conducting customer discovery and assessing product-market fit.

Here, we detail the inaugural, and successful, instance of B2BB, which took place from June to July 2020. In this first cohort of 54 students, 53 completed the program and 38 entered the MSM online Master of Science in Biotechnology (MSBT) degree program, increasing enrollment more than fivefold over recent years. These figures, and the high level of satisfaction reported in post-program surveys, are promising signs that B2BB will positively affect diversity and representation in the biotechnology workforce through graduate education. Further, B2BB can serve as a template for future initiatives to facilitate diversity and inclusion in science, technology and medicine (STEM)-related industries and entrepreneurship.

\section{Biotech industry offerings}

From drug development to biologics production, from plant and animal science to medical devices, biotechnology is everywhere. It is currently a $\$ 550$ billion global market and is expected to reach $\$ 727$ billion by 2025 despite the COVID-19 pandemic, with the top three areas being oncology, anti-diabetics and anti-rheumatics ${ }^{1,2}$.

The biotech industry value chain abounds with myriad career opportunities ${ }^{1-4}$. The industry requires talent in many areas, from discovery through market-for medicines, vaccines, diagnostic tests, medical devices and agricultural products-all of which require innovation, validation, business development, handling regulatory affairs and more. Careers in these areas bring value to multiple sectors through collaborations between academia and industry, startup companies and large multinationals, across wide geographic areas. Biotechnology thus offers a broad variety of career tracks and environments ${ }^{2}$.

The industry is interdisciplinary, offering opportunities beyond science and engineering. Talented individuals with combinatorial skills that include hard science are needed throughout the governance processes in these pipelines to ensure that products and services meet standards for quality, regulation, safety and compliance ${ }^{1}$. Diverse voices are also needed in the business development of biotechnology-in marketing, finance, drug pricing, manufacturing, operations, logistics and connectivity. Technology-centered and technology-enabled 'disruptive areas' - those that create new markets and may eventually disrupt existing markets-present an array of opportunities for computer scientists, informaticians and members of fields not traditionally associated with pharmaceutical R\&D. Biomedical data science ${ }^{5}$ can guide the screening of new drugs, and 'big data' analysis ${ }^{1}$ can provide unprecedented insight into disease and the behavior of populations.
Importantly, as human-centered specialties gain ground in the biotech industry, companies must find links between the quantity and quality of diverse human experiences and their associated health and consumer outcomes ${ }^{1,3}$. These human experiences include workforce, partnership, and patient and customer experiences, and these efforts require individuals skilled at extending relationship-building beyond traditional patient advocacy.

The COVID-19 pandemic has brought to the fore the essential role of the biotech industry. Many projections from 2019 no longer apply. Although the industry's size and productivity have not significantly changed ${ }^{2}$, its influence in the public consciousness for developing new vaccines and medicines for the prevention and treatment of COVID-19 and future pandemics has been outsized ${ }^{6}$.

\section{Social movements of the summer of 2020}

For a number of reasons, the spring and summer of 2020 ushered in decentralized social and political movements. Together, these civil protests in the streets and corporate boardrooms advocated for change not only in how police treat African Americans, but also in workforce diversity and access to opportunities in industries previously not welcoming to, and in some cases hostile toward and/or exclusive of, African Americans ${ }^{7}$. Personal testimonials have revealed that many corporations have historically been wary of conflict, but the racially motivated violence against people of color by publicly funded police, against the background of the COVID-19 pandemic, created a tipping point in both US civil society and corporations ${ }^{8}$. The World Economic Forum created the Diversity, Equity and Inclusion Toolkit, while companies pledged hundreds of millions of dollars to foster a culture of diversity and inclusion in their workforces ${ }^{9-11}$. 
The call for a talented and diverse workforce is therefore louder than ever. Clinical trial enrollment has decreased across the board, new investments have declined due to the economic situation, and facilities and personnel are, in general, more heavily taxed ${ }^{2}$. Of course, the biotech industry is churning out products faster than ever to meet the pandemic's demand. In addition to treatments and vaccines, new economic and business models to foster prevention and ease the financial burden of the virus are also being developed ${ }^{2}$. In the United States, Operation Warp Speed, "a public-private partnership whose goal is to deliver 300 hundred million doses of safe and effective COVID-19 vaccines by the end of [2020]," continues to provide new opportunities in research, preclinical preparation, clinical trials, approval, manufacturing and distribution ${ }^{12}$. Geographic opportunities are also expanding, as companies with geographic diversity can better accommodate shifting situations. Therefore, the biotech sector has long-term robustness despite near-term challenges, thanks to supportive governments and investors who understand the long-term timeline and complexity of therapeutics and vaccine development.

\section{Diversity in the biotech industry}

The state of the world requires diverse perspectives to solve complicated problems, but sadly, the US biotech workforce does not reflect the population it serves. In a 2020 survey of 42 US biotech companies by the Biotechnology Innovation Organization (BIO), $4 \%$ and $5 \%$ of employees self-identified as Black or African American and Hispanic/Latinx, respectively, whereas $59 \%$ identified as white, even though Black and Latinx people represent $13.5 \%$ and $18 \%$, respectively, of the US population. The numbers were even more disparate among positions of power: $1 \%$ of executives, $3 \%$ of board members and $3 \%$ of CEOs identified as Black or African American. Similarly, 1\% of executives, $3 \%$ of board members and $3 \%$ of CEOs identified as Hispanic/Latinx. In contrast, $82 \%$ of executives, $68 \%$ of board members and $88 \%$ of CEOs identified as white $^{13}$. The situation has not improved since a 2018 survey by BIO in collaboration with Nature Biotechnology $y^{14}$.

Given that the industry's products and services serve all demographics, its workforce needs to represent the nationwide population it serves ${ }^{3,13}$. Underserved populations have carried disproportionate burdens of disease, and the COVID-19 pandemic has highlighted this fact ${ }^{15-17}$. In a 2020 study of urban areas afflicted by COVID-19, people living in predominantly
African American counties were three times more likely to become infected than people in predominantly white counties. People living in predominantly Black counties were six times more likely to die from COVID-19 than people in predominantly white counties ${ }^{18}$.

Increasing representation of under-represented minorities (URMs) and underserved populations in the workforce benefits business and society as a whole. We can identify more effective treatments when participants in clinical trials for drugs and vaccines more fully represent the patients who might receive the products ${ }^{3}$. Furthermore, members of URMs and other underserved populations are inclined to practice in underserved areas ${ }^{17,19,20}$. Research on the medical workforce has demonstrated that, upon returning to their communities, they also improve overall health outcomes by destigmatizing medical practices that have caused non-compliance and poor health outcomes due to their association with historical abuses of marginalized populations ${ }^{19,20}$. To continue with the example of medicine, increasing the numbers of URM and other underserved population members with advanced degrees can lower generational poverty, as the degree opens opportunities into well-paying careers $^{19}$. Individuals with training in biotechnology may springboard into any of a number of existing well-paying careers or create new ones. Increasing representation in biotechnology thereby serves society by both narrowing socioeconomic disparities and improving health outcomes.

To realize the benefits of increasing representation, it is necessary to understand the reasons behind the disparities, in order to remove them. Research into these questions in biotechnology has been limited, but general trends in education and advanced degrees are readily translatable to the field. These include historical inequities, low literacy, low educational attainment and the subtle but invasive bigotry of low expectations ${ }^{19,21}$. Many locations have experienced vicious cycles due to resegregation and generation gaps. Resegregation has occurred as well-off students left public schools for private schools. Low education and awareness in older generations have led to lack of academic support and pressure to get jobs for younger generations ${ }^{22}$. Furthermore, members of URMs presented with educational opportunities outside their communities have experienced geographic and/or social isolation that can stymie interest, motivation and confidence ${ }^{22-24}$.

In health fields, programming and mentorship are the biggest predictors of success in overcoming these barriers ${ }^{19,20,22,25}$. Programming has provided environments to raise awareness of career opportunities, overcome social isolation, provide mentors and psychosocial and academic support, and increase expectations, which have been shown to lead to success and high self-concept. More than $80 \%$ of participants in the Health Equities Scholars Program at the University of Massachusetts graduated college, double the graduation rate of students of color who did not attend the program, over the four years of the study ${ }^{20}$. Between 1997 and 2001, 96\% of graduates of the Health Sciences and Technology Academy, an educational pipeline to address health care disparities in West Virginia, attended college, and $90 \%$ of program graduates returned to serve their historically underserved communities in West Virginia ${ }^{17}$. Graduates of pipeline programs have reported improved communication skills and confidence through teamwork and tutor-supported activities ${ }^{19,21}$. The consequences were dramatically higher enrollments in medical, dental and nursing schools and doctoral degree programs among pipeline program graduates compared to nationwide averages ${ }^{21-23}$. Remarkably, 95 of 115 educationally disadvantaged students rejected by medical schools were admitted into medical school after attending a 10-week summer reapplicant program at the University of California, Davis, and reapplying ${ }^{26}$.

At this time, programming and mentorship in biotechnology are either underdeveloped, underpromoted or both. Pipeline programs in biotechnology and bioentrepreneurship are scarce and must be built up to improve outcomes and to reduce generational poverty, as studies have shown that more diverse teams yield better products and services ${ }^{14}$. Across all pipeline programs, participants report that the most important factors in their experience were mentors, psychosocial support and academic support ${ }^{23,25,27}$. These factors were key to increasing exposure and awareness, to providing new ideas for careers and to raising career-readiness and a sense of community ${ }^{20,25}$. Research has shown that it is paramount to feed students' curiosity, self-confidence and self-worth; otherwise they are unlikely to feel motivated for further involvement ${ }^{17,23,25,27}$. When these areas improve, participants feel empowered to implement strategies to improve health in their own communities ${ }^{19,20}$. These areas are thus the cornerstones for the pipeline program that we built.

We built the Bridges to Biotechnology and Bioentrepreneurship at the Morehouse School of Medicine to answer the loud 
call to action for pipeline programs in biotechnology ${ }^{28}$. The objectives of this five-week program were to raise awareness of the biotech field and its offerings and to help more students transition into the industry through eventually earning a Master's degree. We built upon the same principles as successful pipeline programs in advanced degrees and broader STEM fields at all phases of education. This program successfully raised awareness and interest in biotechnology and bioentrepreneurship among participants, so much so that 38 , or $71 \%$ of the 53 students who completed the program, enrolled in the one-year Master of Science in Biotechnology program at MSM, increasing enrollment in the MSBT program fivefold from previous years.

\section{Creation of the B2BB program}

We designed B2BB to prepare students for the MSM MSBT program, for the biotech industry and/or for starting their own bioventures. For practical purposes, it also prepared students for an online curriculum, as the follow-on Master's degree program was conducted entirely online. To give students first-hand exposure to biotechnology, the program engaged them with current events-especially the COVID-19 pandemic and the social unrest during the summer of 2020.

The program positioned students to immediately begin the MSBT at MSM at the conclusion of $\mathrm{B} 2 \mathrm{BB}$. At the time of $\mathrm{B} 2 \mathrm{BB}$ application, students were aware that if they successfully completed the B2BB program, they would automatically be admitted to and receive a $\$ 1,000$ scholarship toward the MSBT degree program.

Recruiting participants. Because graduates of B2BB were automatically admitted to the MSBT program, only applicants who fulfilled the admission criteria for the graduate program were considered for B2BB. When soliciting applications, we targeted under-represented students, especially African Americans and members of other underserved populations anywhere in the United States. We were unable to admit any students from outside the United States because their qualifications did not meet those for the MSBT program. Applicants were juniors or seniors in college at the time of application who showed interest in the field of biotechnology and who preferably had a strong record in science or math. Postbaccalaureates interested in pursuing a career in the biotech industry or with entrepreneurial interests were also considered. Most applicants had majors in science, technology, engineering, arts or mathematics, with explicit interest in healthcare or biomedical services.

We received 326 applications, interviewed 130 applicants and enrolled 54 students into the B2BB program. We interviewed applicants who submitted a complete application, including two letters of references; who had a grade point average (GPA) $\geq 2.8$ (consistent with the requirement for the MSBT program); and who answered "Yes" when asked about their interest in joining the MSBT program.

Interviews lasted ten minutes and included a panel of five interviewers, including creators of the program. Students were asked: (i) "Why do you want to join B2BB?"; (ii) "How will it help your long-term goals?" and (iii) "If not selected for B2BB, will you still apply for the MSBT program?" On a practical level, we also verified students' availability during the term of the program. Students also needed to commit to the requirements of our B2BB program: to miss no more than two sessions, to complete weekly graded assignments and a research project and to respond to pre- and post-program surveys.

The admissions team recommended interviewees to join the B2BB program based on their academic fitness on a scale of $1-5$, which was based on their responses during the interview, letters of recommendations in their applications and interest in matriculating in the fall or spring MSBT program following B2BB.

\section{Curriculum design and rationale.}

Briefly, the curriculum consisted of an orientation, seven topic-specific modules and a culminating event during which entrepreneurship teams pitched their business propositions. The orientation gave students an overview of the program, personal introductions, online etiquette used throughout the program and what it means to define a value proposition.

The first module, "Research Basics," covered the basic components of a research grant and project, essential principles of research using animal models and human subjects, and necessary lab safety and etiquette. The "Project Management" module introduced students to the project life cycle and project management processes and distinguished among projects, programs and routine tasks. In the "Career Readiness" module, students began writing job-specific resumes, cover letters and personal statements, and received feedback and interview preparation practice with special attention on developing critical thinking and problem-solving mindsets.

"Making Medicines: The Process of Drug Development" was a week-long intensive, second module covering the life cycle and regulatory and ethical issues involved in developing drugs. Specifically, this module aimed to illuminate the roles and contributions of pharmaceutical companies in advancing new therapies, and the general pathway from drug discovery to the marketplace. We remain extremely grateful for support for this module from Eli Lilly \& Company. The module provided (i) an overview of drug development and regulatory approval, drug discovery, a rational approach to drug development, non-clinical and early clinical testing, late-stage clinical trials, the drug approval process and continuous clinical development, i.e., phase 4 clinical trials. A case study module on the COVID-19 pandemic aimed to bring all participants up to date on the current research-based understandings of the virus' biology, epidemiology and clinical symptomatology. Following these updates, the module reviewed general principles of vaccine design and the latest innovations in developing vaccines against COVID-19.

"Making Medicines" was followed by a module on "Laboratory Safety" and regulatory best practices-Good Laboratory Practice (GLP), Good Clinical Practice (GCP) and Good Manufacturing Practice (GMP). The learning objectives were for students to understand best practices relevant to any biotech-related business in the United States. They were expected to understand root cause analysis; to explain the different classes of hazards, hygiene plans, exposure limits, safety controls, etc.; to be able to describe key elements of hazard communication; and to understand Occupational Safety and Health Administration (OSHA) limits by the end of the B2BB program.

A "Public Health Informatics Boot Camp" module gave students hands-on exposure to coding, working with statistics, MySQL databases, languages of the internet (HTML, XML and JSON), the basics of data analysis and Python coding, and group project presentations using data from the Centers for Disease Control on COVID-19. A silver lining from this pandemic is that considerable data and information were available, allowing us to incorporate these datasets into our program.

After a preparatory module called "Lean Biotech Start-up \& Entrepreneurship: I-CORPS and the Path to Commercialization," students embarked on their final project, "Value Proposition and Business Model of a Biotechnology." These projects gave students an immersive experience in the pipeline for creating a product or service in biotechnology, with 
defining a value proposition and customer discovery as the core exercises. During this module, students spent substantial amounts of time talking with customers and testing their biotech business hypotheses. They regularly submitted a record of their team's discovery process to the instructors and gave daily five-minute presentations about their progress. The module culminated in a 'pitch' day, when teams highlighted their business premises and the value propositions of their minimum viable products. This aspect of the $\mathrm{B} 2 \mathrm{BB}$ program reached beyond the offerings of other pipeline programs of which we are aware because it prepared students for additional advanced degrees, such as medicine, dentistry, nursing and $\mathrm{PhD}$ degrees, as learning what is valued in different biotech sectors reinforced their working and practical knowledge of allied health disciplines. This particular module stands out by exposing students to essential elements of business-forming a business model, developing and testing business hypotheses and forming relationships with key opinion leaders (KOLs). Thus, the B2BB program provided an experience that reflects current activities in the biotech industry more than any existing pipeline program.

We note that external partnerships were critical toward these goals. This first external partnership of the B2BB program was with Eli Lilly. Importantly, the "Making Medicines" module included a day lecture and exercises with a radio and television host, Rashad Richey, who gave an overview of how to navigate political issues around healthcare and health equity, along with marketing and personal and product branding.

In addition, receiving 326 applications vastly exceeded our expectations, as we originally anticipated having only 15 participants for this first cohort. To help us accommodate this overwhelming interest, the United Negro College Fund provided financial support that allowed 54 students to enter B2BB. Notably, 30 of the 106 survey respondents $(28.3 \%)$ were first-generation college students.

\section{Assessing outcomes: pre- and post-program surveys}

The outcomes of B2BB were mainly represented by the number of graduates who enrolled in the MSBT program at MSM, and the responses to surveys filled out by the participants before starting the program, after each module and at the end of the program. We queried the participants' demographics and academic histories. Of the 326 applicants, 106 responded to the pre-program survey; among them, 86 reported as African American,

a

Respondents by race or ethnicity in 2020,
$N=101$

b Respondents by age range in 2020 ,
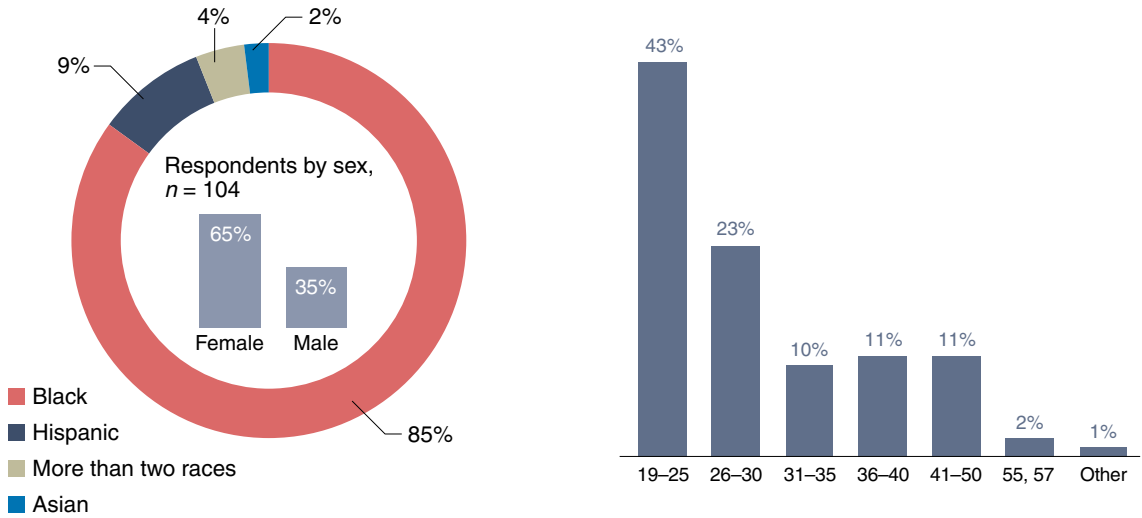

Fig. 1 | Self-identified race/ethnicity, gender and age of B2BB applicants who responded to the pre-program survey. $\mathbf{a}$, Race and/or ethnicity of the respondents. Inset: gender of the respondents. b, Age of the respondents.

9 Hispanic, 5 unknown, 4 of two or more races and 2 Asian. Among the respondents, 68 were female, 36 were male and 2 did not respond. The respondents' self-identified race or ethnicities, sex and age ranges are summarized in Fig. 1.

The pre-program survey also checked that the applicants' interests aligned with the offerings of the program, summarized in Fig. 2. Indeed, 53 (50\%) respondents indicated that they were most interested in medicines and $26(24.5 \%)$ indicated most interest in medical devices, covering the main focal areas of the $\mathrm{B} 2 \mathrm{BB}$ program. Taken together, results from the pre-program survey showed substantial interest in biotechnology and bioentrepreneurship among African Americans and other underserved populations, indicating that the under-representation of these groups in the industry is due not to lack of interest but to institutional and societal factors that must be overcome.

Students also completed post-module surveys, which asked them to rate the module overall on a scale from 1 to 5 , with 1 being "it could be better" and 5 being "amazing"; to rate their overall satisfaction with the module (very satisfied, somewhat satisfied, neutral, disappointed, strongly disappointed); and to give more specific feedback about the module. These specific areas were content relevance, length of presentations, quality of the presenter, accessibility to documents, ability to have questions answered and navigating through the Canvas software platform. Students were also asked to rate on a 5-point scale (strongly agree, agree, neutral, disagree, or strongly disagree) a Interests in different biomedical research areas in 2020, $N=101$

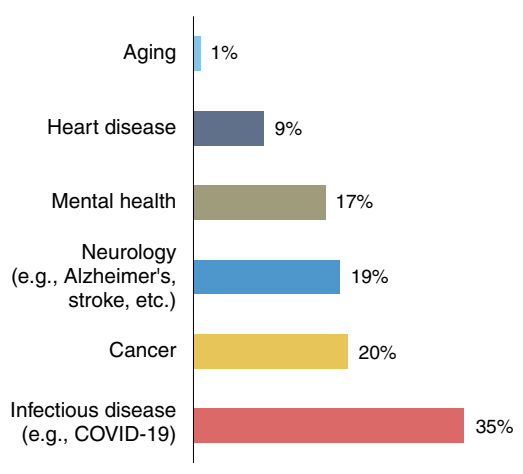

b Interests in different biotech in product areas in 2020, $N=101$

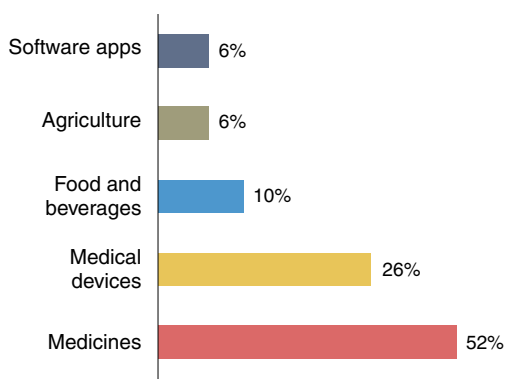

Fig. 2 | Interests of B2BB applicants who responded to the pre-program survey. a, Areas of interest in biomedical research. $\mathbf{b}$, Areas of interest in biotechnology products.

their response to the phrase "The module helped me understand ___." For freeform responses, students were asked to list areas for improvement, to name material that 
needed more coverage, to name topics that they found interesting and would like expanded on and, finally, to give any additional comments they would like to share. The modules were also assessed in the post-program survey through questions asking students to name their favorite modules and rank the modules from most favorite to least favorite.

The post-program survey primarily asked students to evaluate the program as a whole. In addition to rating their overall satisfaction, students rated specific areas including the application process, content relevance, responsiveness, timing, navigation of the online software and ability to receive help from the program's administrators. Additional questions they responded to (on the same 5-point scale from strongly agree to strongly disagree) included "I feel better prepared if I were to attend the Master of Science in Biotechnology degree program" and "The Bridges to Biotechnology and Bioentrepreneurship program helped me to better understand biotechnology and/or bioentrepreneurship at large"statements speaking directly to the program's main objectives.

Free response questions in the post-program survey included listing areas that the students felt were particularly helpful in strengthening their knowledge of biotechnology and areas where they would like to receive additional information, as well as evaluations of the course components, such as lectures, assignments, organization and course materials.

The survey also included statements about the effects of the program for which the students were asked to rate their level of agreement. These statements included "B2BB was challenging," "B2BB made me think," "B2BB increased my interested in this field" and "B2BB gave me confidence to do more advanced work." Similar types of questions were asked about the instructors, regarding whether the instructors created welcoming and inclusive learning environments, communicated clearly and stimulated students' interest, and whether students could get help when they needed it.

\section{Program outcomes}

This first instance of the B2BB program produced promising outcomes. Out of 54 juniors and seniors in college who enrolled in B2BB, 53 (98\%) completed the program. Among the 53 graduates, 38 (71\%) enrolled in the MSBT program, substantially increasing the starting class size to 48 students, compared with 9 students the previous year. This more than fivefold increase in enrollment in the MSBT

Table 1 | B2BB participants' answers to post-program survey questions about their post-program outlook and satisfaction with the program

\begin{tabular}{|c|c|c|c|c|c|}
\hline Question & $\begin{array}{l}\text { Strongly } \\
\text { disagree }\end{array}$ & Disagree & Neutral & Agree & $\begin{array}{l}\text { Strongly } \\
\text { agree }\end{array}$ \\
\hline $\begin{array}{l}\text { The Bridges to Biotechnology and } \\
\text { Bioentrepreneurship program helped me } \\
\text { to better understand biotechnology and/or } \\
\text { bioentrepreneurship at large }\end{array}$ & - & - & - & $17.2 \%$ & $82.8 \%$ \\
\hline $\begin{array}{l}\text { I feel better prepared if I were to attend } \\
\text { the Master of Science in Biotechnology } \\
\text { degree program }\end{array}$ & - & - & $8.5 \%$ & $16.9 \%$ & $74.6 \%$ \\
\hline $\begin{array}{l}\text { It is my desire to enroll in the Master of Science } \\
\text { in Biotechnology degree program at MSM, } \\
\text { if not fall, sometime in the future }\end{array}$ & $1.7 \%$ & $1.7 \%$ & $6.8 \%$ & $11.9 \%$ & $78.0 \%$ \\
\hline
\end{tabular}

Table 2 | B2BB participants' answers to post-program survey questions relating to the effects of the program

\begin{tabular}{llllll} 
Statement & $\begin{array}{l}\text { Strongly } \\
\text { disagree }\end{array}$ & Disagree & Neutral & $\begin{array}{c}\text { Agree } \\
\text { Strongly } \\
\text { agree }\end{array}$ \\
\hline $\begin{array}{l}\text { B2BB was challenging } \\
\text { B2BB made me think }\end{array}$ & $1.7 \%$ & $1.7 \%$ & $6.8 \%$ & $50.8 \%$ & $39.0 \%$ \\
$\begin{array}{l}\text { B2BB has increased my interest in this field } \\
\text { of study }\end{array}$ & - & - & $1.7 \%$ & $50.8 \%$ & $39.0 \%$ \\
$\begin{array}{l}\text { B2BB gave me confidence to do more } \\
\text { advanced work in the subject }\end{array}$ & - & $1.7 \%$ & $8.5 \%$ & $16.9 \%$ & $72.9 \%$ \\
\hline
\end{tabular}

program is a promising sign that the $\mathrm{B} 2 \mathrm{BB}$ program may increase diversity in the biotech workforce.

Based on the post B2BB surveys, students had a positive experience in the program, summarized in Tables 1 and 2. Eighty percent of students reported feeling very satisfied with their experience, $16.4 \%$ reported feeling somewhat satisfied and the remaining $3.6 \%$ (2 students) felt strongly disappointed.

As a quantitative metric for students' inclination to promote B2BB to others, we calculated a net promoter score (NPS). The NPS measures the loyalty that exists between an enterprise, in this case B2BB, and its customers, the students. Students were asked to respond on a scale of $1-5$, with 5 being most likely, to the question "How likely are you to recommend MSM Bridges to Biotechnology and Bioentrepreneurship program to a friend or colleague?" Values of the NPS range from -100 to +100 , with positive scores indicating positive loyalty, scores above 50 considered excellent and scores above 70 considered exceptional. The NPS score among this first cohort was 79 , surpassing the threshold considered exceptional. Among the respondents, 48 were promoters, 10 were passives (neither promoters nor detractors of the program), and 1 respondent was a detractor. Recurring words in the free responses included informative, helpful, impeccable, well-rounded, well-organized and excellent.

Based on the reports from students, we identified four main achievements of the program. First, students reported feeling better connected to biotechnology, with $100 \%$ of survey respondents agreeing that "The Bridges to Biotechnology and Bioentrepreneurship program helped me to better understand biotechnology and/or bioentrepreneurship at large." Among them, $82.8 \%$ answered "strongly agree." Second, the program increased students' drive to learn more about biotechnology, with over $90 \%$ agreeing or strongly agreeing with the statement "It is my desire to enroll in the Master of Science in Biotechnology degree program at MSM, if not fall, sometime in the future" (Table 1). Third, students reported increased excitement about starting their own bioventure or biotech startup, naming new insights into how to create a product and the customer discovery process. Finally, the survey results and enrollments indicate that $\mathrm{B} 2 \mathrm{BB}$ has increased the potential for a more diverse workforce in biotechnology in the coming years due to more and better-prepared graduates. Nearly $90 \%$ intended to enroll in the MSBT program 
at MSM some time in the future, with $78 \%$ answering "strongly agree" to a question addressing their interest in the program at the end of $\mathrm{B} 2 \mathrm{BB}$.

Main points for improvement requested by the students related to the volume of information, with specific mention of more depth over breadth for the "Making Medicines" module and of reformatting the bioentrepreneurship project. Students generally agreed that the program disseminated large volumes of information that could have been more focused and timed differently so that they could better absorb and retain it. Some students would like to have received the material farther in advance from the time it was taught to allow them to prepare more. Most but not all modules included a lecture component, which students perceived as helpful, and they urged program organizers to include a lecture in every module during future iterations of the program.

Student feedback indicated that the "Making Medicines" module could be restructured to cover more depth rather than breadth. Students found the module interesting but too extensive in its breadth of information, and would have preferred more depth on drug discovery and the US Food and Drug Administration approval process. Survey responses also suggest that the assignments for this module were ambiguously written and inconsistent with the content on the slides for self-learning.

For the Mini I-CORPS and Bioentrepreneurship Projects, both students and facilitators felt that these were rushed. Containing these projects in the final two weeks of the program limited the amount of work that could be done, especially in interviewing KOLs, as some KOLs were unavailable or unresponsive during this time window. Program organizers intend to spread this module out over the five weeks of the program in future to mitigate these difficulties.

\section{Conclusions}

The outcomes of this first instance of the B2BB program at MSM speak directly to the goals of preparing students to go into biotechnology and/or to start their own bioventures. The program increased awareness of the biotech industry's offerings, provided exposure to relevant skillsets, and in doing so increased students' confidence and belief that they themselves were positioned to contribute to solving the crisis at hand. From a practical standpoint, the program set a precedent for online pipeline programs and prepared students well for the all-online MSBT program.
This pilot instance coincided with the worldwide COVID-19 pandemic. The negative impacts of this pandemic, particularly on African Americans and other underserved populations, has arguably provided the most dire modern illustration of perpetual health inequities. However, the COVID-19 crisis also provided primary data for B2BB's case study and its programming and modeling modules. Working with these data to address the same questions as industry professionals gave students a sense that they could contribute immediately to improving health situations in their communities. Students were also inspired by the voices of African American leaders in vaccine development, which ignited awareness of their potential to contribute to solutions. According to student feedback, students left the program empowered with current information and skills they could immediately apply to the crises affecting their communities.

Among pipeline programs, B2BB stands out in its business training through the mini I-Corps module and bioentrepreneurship project. Most existing pipeline programs aim to lead students into advanced degrees-medicine, dentistry, nursing and doctoral-and thus provide students relevant experience, including hands-on research experience, for those fields. To our knowledge, only B2BB provides hands-on business experience translatable to entrepreneurship. The program trained students to brainstorm toward product creation, to interact with external industry partners, and to undertake the customer discovery process including directly contacting KOLs. Thus, students received a well-rounded experience from B2BB that represents their potential experiences in the biotech industry and as entrepreneurs.

Survey responses and subsequent enrollment in the MSBT degree program indicate that $\mathrm{B} 2 \mathrm{BB}$ addresses numerous factors historically responsible for the diversity gap in industry and higher degrees. First, students reported increased awareness. Many reported feeling lost and unaware of the industry's offerings beforehand, which was transformed into awareness through exposure to the program's content. Second, mentoring plays a key role in students' own perceptions of career readiness. Survey responses indicated that they wanted support to improve their curriculum vitae, soft skills, and interviewing, pitching and writing skills. Furthermore, they would have liked to have this expand to cover critical thinking and problem-solving skills. Third, the high level of expectations that the students experienced seemed to feed their drive and discipline, consistent with historical data indicating that high expectations feed healthy notions of success and self-concept $t^{20}$. Fourth, like mentors, instructors also have an important role in students' perception of themselves joining the field. Survey responses indicated that students are inspired by people in the field with a background they can relate to, providing statements like, "It was empowering to see representation leading the charge and having a seat at the table in the scientific arena" and "[the instructor] needs to be the leading Black voice in COVID-19 mitigation and vaccine development among African Americans. Simply awesome and very knowledgeable." Finally, nearly $90 \%$ of B2BB graduates agreed that they left the program with more confidence about doing advanced work in biotechnology, with $72.9 \%$ answering "strongly agree" to the question addressing this point.

The B2BB program is a one-of-a-kind program that gives participants social and science exposure, industry-specific and business training, and confidence that they can apply immediately to today's problems. Over the short term, the program increases awareness and opportunity among individuals from underserved and under-represented groups. Over the longer term, the program connects participants directly with graduate training through the MSBT degree at MSM. This first iteration of $\mathrm{B} 2 \mathrm{BB}$ holds promising signs for opening doors for more talented individuals to have meaningful and potentially lucrative careers in biotechnology and bioentrepreneurship, which could help narrow gaps in health disparities in their communities. Moreover, given the dismal representation at large, this industry has been missing out on the diversity of perspectives needed to understand and to serve diverse populations, a gap that the $\mathrm{B} 2 \mathrm{BB}$ program and its graduates should help mitigate.

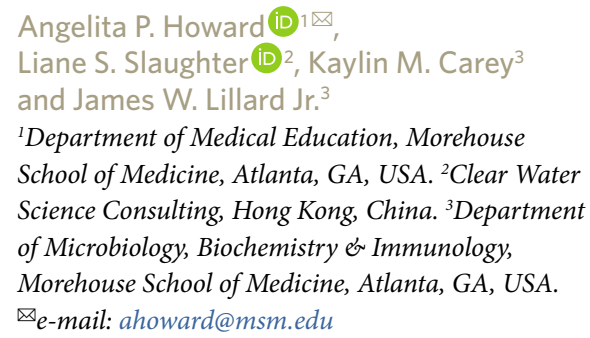

Published online: 9 November 2021 https://doi.org/10.1038/s41587-021-01110-3

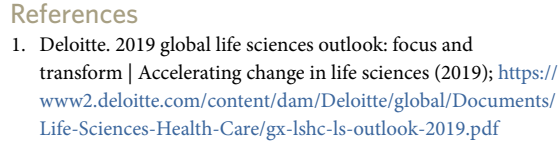


2. Global Business Reports. United States biopharmaceuticals 2020 (2020); https://www.gbreports.com/files/pdf/_2020/ US_Pharma_2020_-_First_Edition_Web_Version_.pdf

3. Deloitte. 2020 global life sciences sector outlook (2020); https:// www2.deloitte.com/global/en/pages/life-sciences-and-healthcare/ articles/global-life-sciences-sector-outlook.html

4. Global Business Reports. United States biopharmaceuticals 2019 (2019); https://www.gbreports.com/files/pdf/_2019/ US_Biopharma_2019.pdf

5. EvaluatePharma. World preview 2019: outlook to 2024 (2019); https://info.evaluate.com/rs/607-YGS-364/images/ EvaluatePharma_World_Preview_2019.pdf

6. EvaluatePharma. World preview 2020: outlook to 2026 (2020); https://www.evaluate.com/thought-leadership/pharma/ evaluatepharma-world-preview-2020-outlook-2026

7. Hutt, R. Amazon and Google among big US companies pledging to hire 100,000 people from marginalized New York communities. World Economic Forum (13 August 2020); https:// www.weforum.org/agenda/2020/08/new-york-companies-hireworkers-low-income-minority/

8. Anonymous. Bosses say they want to tackle racial injustice. Economist (13 June 2020)

9. Markovitz, G. \& Sault, S. What companies are doing to fight systemic racism. World Economic Forum (24 June 2020); https://www.weforum.org/agenda/2020/06/companies-fightingsystemic-racism-business-community-black-lives-matter/

10. Banjo, S. \& King, I. From Apple to Facebook, tech's new diversity pledges follow years of failure. BloombergQuint (23 June 2020); https://www.bloombergquint.com/technology/ apple-amazon-facebook-google-microsoft-data-on-black-hiring
11. Mitchell, A. \& Alwyn, S. Building economic opportunity for Black communities. Netflix press release (30 June 2020); https:// about.netflix.com/en/news/building-economic-opportunityfor-black-communities

12. US Department of Health \& Human Services. Fact sheet: explaining Operation Warp Speed (2020); https://health.mo.gov/ living/healthcondiseases/communicable/novel-coronaviruslpha/pdf/fact-sheet-operation-warp-speed.pdf

13. Biotechnology Innovation Organization. Measuring diversity in the biotech industry: building an inclusive workforce (2020); http://go.bio.org/rs/490-EHZ-999/images/Measuring_Diversity in_the_Biotech_Industry_Building_an_Inclusive_Workforce.pdf 14. Huggett, B. Nat. Biotechnol. 36, 20-30 (2018).

15. Johnson-Agbakwu, C. E. et al. J. Racial Ethn. Health Disparities https://doi.org/10.1007/s40615-020-00928-y (2020).

16. Phillips, N., Park, I.-W., Robinson, J. R. \& Jones, H. P. J. Racial Ethn. Health Disparities 8, 1153-1160 (2021).

17. McKendall, S. B., Kasten, K., Hanks, S. \& Chester, A. Acad. Med. 89, 37-42 (2014)

18. Yancy, C. W. J. Am. Med. Assoc. 323, 1891-1892 (2020).

19. Bright, C. M., Price, M. A., Morgan, R. C. Jr. \& Bailey, R. K. Montague Cobb/NMA Health Institute Consensus Panel on the Plight of Underrepresented Minorities in Medical Education. J. Natl Med. Assoc. 110, 614-623 (2018).

20. Upshur, C. C. et al. J. Racial Ethn. Health Disparities 5 342-350 (2018)

21. Hollar, D. \& Keith, L. Educ. Health 25, 55-63 (2012)

22. Formicola, A. J., D’Abreu, K. C. \& Tedesco, L. A. J. Dent. Educ. 74 (Suppl.), S67-S73 (2010).

23. Gibau, G. S. et al. J. Women Minor. Sci. Eng. 16, 215-235 (2010).
24. Ware, A. D. et al. Acad. Pathol. 6, 2374289519873104 (2019). 25. Avent, C. M. et al. J. Biomech. Eng. 140, 084701 (2018) 26. Blakely, A. W. \& Broussard, L. G. Acad. Med. 78, 437-447 (2003).

27. Brooks Carthon, J. M., Nguyen, T.-H., Chittams, J., Park, E. \& Guevara, J. Nurs. Outlook 62, 259-267 (2014).

28. Morehouse School of Medicine. Bridges to Biotechnology and Bioentrepreneurship (2021); https://www.msm.edu/online/ BridgestoBiotechnologyPipelineProgram/

\section{Acknowledgements}

This program was funded in part by a grant from the United Negro College Fund and by US National Cancer Institute grant U54CA118638. The authors thank Grace Sun, Pat Hinton Walker and Tracy Lee Gilman for discussions to improve the manuscript

Author contributions

A.P.H. conceptualized, designed surveys, acquired data, analyzed and interpreted data and prepared the manuscript. L.S.S. interpreted data, proofread and edited the manuscript. K.C. prepared figures and edited the manuscript. J.W.L. interpreted data and edited the manuscript.

Competing interests

The authors declare no competing interests. 